\title{
Strategies for Promoting Initiative Communication of Autistic Children in Kindergarten Inclusive Education
}

\author{
Lan Zhang \\ Minzhi Road Kindergarten, Suzhou, China \\ Email address: \\ 29966933@qq.com
}

\section{To cite this article:}

Lan Zhang. Strategies for Promoting Initiative Communication of Autistic Children in Kindergarten Inclusive Education. Education Journal. Special Issue: Pathway to Quality Preschool Education: Chinese Perspectives. Vol. 9, No. 2, 2020, pp. 52-58.

doi: $10.11648 /$ j.edu.20200902.14

Received: March 9, 2020; Accepted: April 3, 2020; Published: May 14, 2020

\begin{abstract}
In kindergarten inclusive classes, the consciousness of initiative communication for most of the autistic children is weak, while initiative communication is precisely one of the indispensable conditions for autistic children to integrate into their classes. Minzhi Road Kindergarten of Suzhou has been devoted over years to the experimental research of pre-school inclusive education for autistic children, and has thus accumulated ample experimental experiences and case study materials. By adopting a variety of research methods including observation, interview, case study, etc., this study takes action research on several individuals previously and currently still enrolled in the kindergarten, and adjusts constantly the interventional programs of promoting initiative communication of autistic children. Eventually this study summarizes three strategies for promoting initiative communications amidst autistic children in kindergarten inclusive education: (1) Understanding the essence of "snatching" behaviors of autistic children and delivering communication skills; (2) Promoting initiative communication for autistic children through inspiration of internal needs to "participate"; (3) Fostering their communication confidence by way of building a performance platform for "advantages" of autistic children. This action research indicates that appropriate strategical interventions from teachers in inclusive classes can promote the initiative communication of autistic children and improve their relationships with peers. Suggestions about further study in the future are discussed in the end.
\end{abstract}

Keywords: Autistic Children, Kindergarten, Inclusive Education, Initiative Communication, Strategies

\section{Research Background}

\subsection{Development Background of Preschool Inclusive Education for Autistic Children in China}

Compared with developed countries, the development of preschool inclusive education for autistic children in China has a late start and is yet incomplete. Whereas in recent years, related governmental departments, normal universities and kindergartens have made jointed efforts together to continuously invest and research in their own work fields, which makes a rapid development of preschool inclusive education for autistic children real.

The State conducts panoramic guidance and overall planning in terms of policies, and increases investment on preschool inclusive education constantly. For instance, article 26 of chapter two of the Law of the People's Republic of China on Basic Medical Care and Health Promotion voted through by the $15^{\text {th }}$ session of the Standing Committee of the $13^{\text {th }}$ National People's Congress on 28 December 2019 reads an explicit regulation in this regard "the people's municipal governments at or above county level shall give priority to the rehabilitation of disabled children and combine rehabilitation with education". Take another example, the Second Phase of Special Education Promotion Plan (2017-2020) approved by the State Council on 17 July 2017 requires "to comprehensively promote inclusive education with regular school class learning as the principal part, special education school study as the backbone, and door-to-door education and distance learning as supplements" and emphasizes that "regular schools and special education schools shall co-bear responsibilities, share resources and support each other mutually."

Normal colleges and universities are committed to 
strengthening the construction of teacher panel of preschool inclusive education for autistic children and striving to optimize the implementation environment of inclusive education. For example, the standards for teachers of preschool inclusive education have been formulated, special education courses for preschool education major have been offered, and the major of preschool inclusive education has been added in normal colleges and universities to promote the pre-service training of preschool inclusive education teachers in China. [1] Another example, in view of the realistic problems in current preschool inclusive education in China that teachers for pre-service training are insufficient, demands for post-service training are huge and the existing post-service training mode is unitary etc., in-depth researches on teacher training have been carried out. [2]

Kindergartens are the "main battlefields" of preschool inclusive education for autistic children as they are directly confronted with the most severe problems, whereas the fields of the most experimental advantages. Active explorations and researches in many regions over many years have made the development of preschool inclusive education for autistic children personalized. In recent years, there are mainly surveys and researches on current situations of inclusive education for autistic children in certain area. As an example, there are researches of this kind on problems such as the degree of recognition of inclusive education from the kindergarten teachers and the inclusive education models in the city of Tianjin through field observations, questionnaire surveys and interviews. There are also proposals put forward like "kindergarten teachers' recognition of inclusive education to be improved" "relevant scientific research organizations strengthen the research of preschool autistic children's inclusive education" and "the government formulate relevant supportive policies and introduce fund guarantee" etc. [3]. There are researches on teachers of inclusive education for autistic children. For instance, the supportive level of the feelings of teachers from certain inclusive kindergartens and rehabilitation institutions is observed and appraised in the form of contrast groups, factors influencing the supportive quality of the teachers' feelings in preschool inclusive education for autistic children are analyzed from the perspectives of teachers, kindergartens and parents, and advices of promoting the supportive quality of teachers' feelings in inclusive education are propose [4]. In addition, there are case studies of inclusive education on certain autistic child or on certain kindergarten, for example, qualitative research methods being utilized, the current situation of inclusive education in D kindergarten is presented and the problems incurred in implementation in the said kindergarten are analyzed.[5] Take another example, based on the appraisal result, interventional programs on certain cases of autism in the fields of social development and problematic behavior modification are formulated and implemented to improve inclusive education [6]. These personalized experimental researches provide abundant practical examples and fundamental data for actively innovating the models of preschool inclusive education, optimizing the administration of preschool inclusive education and continuously fostering the quality of preschool inclusive education.

However, after longitudinal review of the researches on preschool inclusive education for autistic children over these years, in the field of kindergarten in particular, the author finds that there are yet no in-depth researches covering a number of years and combining many a historic case targeting the social interaction problems incurred in inclusive education for autistic children. Aiming at the prime defects of autistic children, improvement of capabilities of communication and social interaction is of the most importance in inclusive education. Therefore, the researcher focuses on "strategies for promoting the initiative communication amidst autistic children". The kindergarten the researcher works with is empowered with the resources and qualifications to carry out such researches.

\subsection{Implementation Situation of Inclusive Education for Autistic Children in Minzhi Road Kindergarten of Suzhou}

Minzhi Road Kindergarten of Suzhou is a kindergarten with 70 years history. Since 2010, several teachers have already conducted spontaneously preliminary researches on preschool inclusive education for autistic children, mainly utilizing the research methods of observation, home communication and inclusive education experience. Despite limited influential scope, the research obtained support and recognition from families of autistic children. In 2016, Special Education Guidance Center of Suzhou cooperated with our kindergarten, and a systematic study on preschool inclusive education for autistic children was initiated. Therefore, the experimental research of preschool inclusive education for autistic children in our kindergarten experienced approximately three phases: the first phase (2010-2015), teachers from inclusive classes spontaneously provided humanitarian care and tentative help to autistic children; the second phase (2016-2018), preliminary cooperation between Special Education Guidance Center and teachers of inclusive classes was established to collectively promote inclusive education for autistic children; the third phase (2018-present), Special Education Guidance Center accredited resources teachers to conduct professional training to teachers of inclusive classes. The scope of research objects was properly broadened and deep cooperation with other parties was conducted multidimensionally so as to help implement inclusive education for autistic children. For the time being, Minzhi Road Kindergarten of Suzhou has become a paradigmatic experimental base of preschool inclusive education for autistic children in Suzhou city and even in Jiangsu province.

In many years of experiments and explorations, Minzhi Road Kindergarten of Suzhou has enrolled successively more than ten autistic children and accumulated abundant experimental experiences, research skills and case study materials. There are also certain original cases in association with "research on strategies to promote initiative communication amidst autistic children", and relevant 
researches can be carried out.

\section{Research Ideas and Methods}

\subsection{Research Ideas}

This study lasts many years and selects several individuals previously and currently still enrolled in the kindergarten to carry out action research on. First of all, data of communications and interactions between these individuals and their peers in the process of inclusive education was collected on the spot, at the same time, more comprehensive data and materials of the individuals were gathered by way of observations and interviews. Secondly, the collected materials were analyzed through combined methods of quantitative description and qualitative research, based on which the programs of "promoting initiative communication of autistic children" were formulated, and specific interventional strategies were devised. Thirdly, the interventional strategies were trimmed constantly based on the implementation effects of the programs, and finally effective strategies to promote initiative communication of autistic children were summarized.

\subsection{Research Methods}

In the implementation of action research, varieties of research methods including observation, interview, case study, etc. were utilized.

The observation method mainly adopts participatory observation. The researcher, as one of the teachers in inclusive classes where these individuals stem from, conducts the event sampling observation every week and records all the activities in relation to the interactions with their peers in detail. In addition to the emphasized record of abilities to express and communicate, to control emotions and to interact socially, auxiliary record of abilities of cognition, academic performances and self-care etc. of the individual are also made.

The interview method primarily utilizes informal interviews. The researcher conducts observation while participating and obtains relatively more comprehensive information of individuals through informal interviews with parents of autistic children, teachers of another inclusive class, shadow teachers and resources teachers, so as to facilitate a thorough analysis.

Case study method, denotes mostly the analysis and judgement of the current abilities of autistic children to express and communicate and socially interact by way of synthesizing information of all kinds. On this account, the researcher makes specific programs to improve the effect of communication and interaction with their peers for autistic children.

\subsection{Research Objects}

Among the autistic children previously and currently still enrolled in the kindergarten over the years, this study selects three of them in inclusive classes where the researcher taught and teaches as the principal individuals of the study. They possess basic language abilities and can meet the basic prerequisites of this study.

Lele (pseudonym), boy, born in February 2009, was diagnosed autism at the age of three. He received the behavior interventional therapy guided by Applied Behavior Analysis (ABA for short) from age three to six, meanwhile he studied in the kindergarten. In the year of age seven, he retained in senior class of kindergarten for a year. His cognitive abilities are acceptable, and his main problems lie in: notably stereotyped and ritual behaviors, difficulty to control his emotions, hyperactive, lacking in consciousness of initiative expression, and strenuous social interaction, etc.

Tiantian (pseudonym), boy, born in October 2011, was diagnosed autism at the age of three. He received the therapy of Developmental, Individual differences, Relationship — based model (DIR for short, normally know as floor time) from age three to five. At the age of five, the level of his practical growth was equivalent to that of a three-year-old child. He entered junior class of kindergarten (class for three-to-four-year-old children) then to try inclusive education, and stayed in the class until graduation from the kindergarten. Since he entered middle class of Kindergarten, special education screw has accompanied him as shadow teachers irregularly and personalized exercise has been conducted ever since. When he was in senior class of kindergarten, his abilities of self-care, language expression and cognition have been significantly enhanced. Whereas, his abilities of emotion control and anti-frustration were still poor, and he was lacking in confidence.

Nannan (pseudonym), boy, born in October 2013, was diagnosed autism at the age of three. He received the therapy of Developmental, Individual differences, Relationship - based model (DIR for short, normally know as floor time) from age three to five. At the age of five, the level of his practical growth was equivalent to that of a two-three years old child. He entered nursing class of kindergarten (class for two-to-three-year-old children) then to try inclusive education. Currently he is studying in junior class of kindergarten. His age, height, and physique are much beyond that of the children in inclusive classes. The development of his cognitive abilities is acceptable, and his memory persists well, but his attention shifts easily. His abilities of emotional expression and control are poor. He has stereotyped and ritual behaviors and repetitive languages, and is hyperactive.

\section{Research Result}

\subsection{Understand the Essence of "Snatching" of Autistic Children, and Deliver Communication Skills}

Autism Spectrum Disorder, ASD for short, is considered to be a neurodevelopmental disorder with clinical diversity and aetiological heterogeneity, often accompanied by a variety of other diseases [7]. There are two prime core symptoms: social communication defects and restrictive interest $\&$ repetitive 
behaviors. Among the individuals contacted by the researcher, expression and communication barriers are prevailing. They are unable to communicate and interact with people in the way assumingly suitable for the ordinary children of the same age.
In inclusive classes, one of the most commonly seen performances is that autistic children "snatch" toys from their peers.

Table 1. Nannan snatched toy car from other children.

\begin{tabular}{ll}
\hline & The first day Nannan entered into the class, accompanied by his mother, other children were playing toys brought from home. \\
Nannan suddenly rushed into other children and "snatched" the toy car of a boy Tutu. Tutu was stunned in the beginning, and \\
then burst into tears. The teacher communicated with Nannan immediately, requesting him to return the toy car to Tutu. Nannan \\
refused and reacted with strong emotions. Movements such as screaming and lying on the floor emerged and lasted \\
approximately five minutes. Similar situation recurred for many times. \\
The teacher communicated with Nannan's mother, and got to know that Nannan has special interest in toy cars and his experience \\
of communicating and interacting with people other than his family members is insufficient. Ever since, the teacher taught \\
Nannan specific skills and methods of expressing ideas to exchange toys with other children through languages, movements and \\
Interventions of the \\
situation simulations, meanwhile asked Nannan's mother to intensify these communication skills. \\
After half a month of consolidation and trying, Nannan was able to complete the verbal request of exchanging toys under the \\
guidance of the teacher, and other children conquered their fear under the encouragement of the teacher and were also willing to \\
exchange some toys with him. The phenomenon that "Nannan took away other children's toys directly after finishing the \\
designated request without consent from them" happened occasionally.
\end{tabular}

In this case, the researcher finds several characteristics through the incident of Nannan's snatching toy car from other children: Firstly, Nannan coveted belongs of other children out of like; secondly, there were no verbal expressions or opinion enquiries from Nannan before obtaining these items; thirdly, Nannan's movement was thought to be unreasonable or rule breaking by his peers and the latter were frightened; fourthly, such phenomenon still recurred for many times after being simply restrained and there were no substantial improvements; fifthly, Nannan could express requests with acquired sentences after being guided explicitly by the teacher, and peer conflicts softened to a certain extent.

It is proved that expressive language is the major missing part of autistic patients, while the patients themselves discover that it is easier to get others help obtain what they need by their own movements than by communications [8]. And this is precisely the reason for Nannan's "snatching" behavior. When the need for certain items arises, his first choice is to snatch directly other than expressing out. In the eyes of ordinary children, this kind of behavior is "snatching", which is rule-breaking and not recognized by the group. If it is left alone, it will become an obstacle for Nannan to integrate into the class. Therefore, what teachers should do is to teach Nannan as many meaningful communication skills as possible to avoid him falling into deeper loneliness in social interactions. [9]

The teacher's interventions, first of all, lie in communications with his mother to fully understand his special love for toy cars, his difficulties in interpersonal communications, and the degree of his understanding of language communications. Secondly, in delivering the skills of "exchanging toys" between Nannan and other children, and refining to specific languages and movements through situational simulation by way of choosing "exchange toys", a way acceptable by both Nannan and ordinary children as the breakthrough to solve the conflicts. Thirdly, in attracting ordinary children with his toys and encouraging them to exchange toys with Nannan.

These interventions lasted nearly half a month, and his "snatching" behavior was restrained to a certain extent. However, the phenomenon that "Nannan took away other children's toys directly after finishing the designated request without consent from them" emerged. This phenomenon reflects that autistic children can acquire the technical abilities of initiative communication through practice, but cannot fully understand the social reasons there behind. This is also the primary reason explaining the social interactional defects of autistic children. [10] However, the intensification of initiative communication skills is still very integral in inclusive education, which can avoid many conflicts with other children, and is constructive to the acceptance of children with autism in inclusive classes.

\subsection{Promote Initiative Communication for Autistic Children Through Inspiration of Internal needs to "Participate"}

With regards to social interactional abilities, autistic patients may be able to react to communications or orders from other people. However once alone, they can do nothing but sit passively and it is difficult for them to ignite any communication [8]. In inclusive classes, we find that the consciousness of initiative communication for most of the autistic children is weak, while initiative communication is precisely one of the indispensable conditions for autistic children to integrate into their classes. Therefore, teachers should take the general features of regular children and the specialty of autistic children into consideration comprehensively, and seek even create situations able to inspire the needs for social interactions of autistic children to help them exercise appropriative ways of communications and language expressions. As the basic activity approach, game is the best carrier satisfying this requirement. [11] The intervention focuses on two aspects: one is the choice or creation of a game environment that can stimulate autistic children's internal needs for "participation" and "communication"; the other one is the provision of effective "communication" experience on the basis of the children's own languages and social development level. In this way, 
autistic children are more likely to actively absorb some simple communication skills, and have the willingness and confidence to apply them for many times to continuously improve their integration into the class group.

Table 2. Story between Lele and rule game "Flight Chess".

\begin{tabular}{|c|c|c|c|}
\hline & $\begin{array}{l}\text { The first phase: Lele could not play } \\
\text { flight chess, and his request for } \\
\text { participation was rejected. }\end{array}$ & $\begin{array}{l}\text { The second phase: Lele mastered the rules } \\
\text { of flight chess and completed the game } \\
\text { with peers together for the first time with } \\
\text { the help of teachers. }\end{array}$ & $\begin{array}{l}\text { The third phase: Lele was able to apply } \\
\text { the rules of flight chess freely, and } \\
\text { successfully joined in the games of peers. } \\
\text { "Rules reminding" to others emerged. }\end{array}$ \\
\hline Lele's status & $\begin{array}{l}\text { Lele failed to join the group in flight } \\
\text { chess game. He directly took away the } \\
\text { pieces others were playing and moved } \\
\text { them on chess board for many times, } \\
\text { causing others' disgust and reporting to } \\
\text { the teacher. The teacher's suggestion } \\
\text { that Lele join the game was rejected by } \\
\text { other children for the reason that Lele } \\
\text { did not know how to play flight chess. }\end{array}$ & $\begin{array}{l}\text { A week later, Lele was active in the } \\
\text { sub-groups of chess games. He "scrambled } \\
\text { for" chess pieces occasionally. However, he } \\
\text { failed to join in the games from start to } \\
\text { finish. The teacher got to understand that } \\
\text { most children rejected Lele with the reason of } \\
\text { "full occupation". }\end{array}$ & $\begin{array}{l}\text { Two weeks later, basically Lele did not } \\
\text { encounter obvious rejections any more, and } \\
\text { could play flight chess harmoniously with } \\
\text { other children. Lele could say "it is } \\
\text { somebody's turn to roll the dice" for those } \\
\text { who did not master the rules. Sometimes he } \\
\text { would pick up the chess piece of the } \\
\text { reminded child directly and "move" the } \\
\text { square. }\end{array}$ \\
\hline $\begin{array}{l}\text { Teacher's } \\
\text { interventions }\end{array}$ & $\begin{array}{l}\text { The teacher communicated with his } \\
\text { parents in time, asking Lele's mother to } \\
\text { teach Lele flight chess at home. Three } \\
\text { days later, Lele mastered basic rules. } \\
\text { The teacher continued observing Lele's } \\
\text { performances in chess time. }\end{array}$ & $\begin{array}{l}\text { Noticing that mild tempered Xiaorong } \\
\text { planned to play flight chess alone, the teacher } \\
\text { requested to join in the game with Lele. The } \\
\text { teacher recommended Lele after confirming } \\
\text { that Xiaorong needed a playmate and stressed } \\
\text { that Lele had mastered the rules of flight } \\
\text { chess. The teacher encouraged Lele to } \\
\text { express his request: "Xiaorong, I would like } \\
\text { to play flight chess, do you agree?" Xiaorong } \\
\text { agreed. Lele obeyed the rules when playing } \\
\text { and the game went on smoothly. However, } \\
\text { there were no verbal communications } \\
\text { between them from beginning to end. }\end{array}$ & $\begin{array}{l}\text { When Lele said "it is somebody's turn to } \\
\text { roll the dice" the teacher affirmed Lele with } \\
\text { words, such as "Lele reminded someone to } \\
\text { roll the dice, it's great!" At the same time, } \\
\text { children who were reminded were asked to } \\
\text { thank Lele. As for Lele's behaviors of } \\
\text { picking up other children's chess pieces and } \\
\text { moving forward according to the rules, the } \\
\text { teacher stopped them and asked Lele to } \\
\text { remind them with languages instead of } \\
\text { directly playing the chess replacing them. }\end{array}$ \\
\hline
\end{tabular}

In this case, the reason why the teacher chose the rule game "flight chess" as the primary interventional approach is that on one hand, games are more likely to arouse interest of children; on the other hand, Lele's execution of rules developed well, and may achieve his goals more easily. Thus, his feelings of success and confidence of initiative communication and participation were fostered.

The researcher finds that Lele's desire to participate in the games makes "playing chess with peers" a situation of the potential possibility to arouse Lele's social interaction. The obstacle is that Lele did not have appropriate languages and behaviors for enquiries, and lacked in the skills of playing flight chess. Therefore, what the teacher needs to do is, to help Lele maintain the internal need of "participating in playing chess" to ignite the wish for initiative communications, and meanwhile to strengthen the guidance of communication skills to promote his social interactions. In the first phase, the teacher helped Lele master basic rules of flight chess in short notice of time with assistance from his parents; in the second phase, the teacher guided Lele to initiate communications with appropriate expressions. The teacher chose on purpose the mild tempered Xiaorong as the object of Lele's first association, making advantage of the opportunity that Xiaorong needed a playmate, and taught Lele language expressions asking for Xiaorong's permission. [12] These efforts made Lele communicate smoothly for the first time, basically built a friendly environment, and Lele's social interactions aiming at flight chess initially succeeded. The progress in the third phase was surprising. As some children did not know the rules of the game, which resulted in a pause during the process of the game. At this time Lele said: "now it's up to somebody to roll the dice". Although the intention of Lele's saying was to implement the rules rather than really reminding and guiding his peers, it's indeed a kind of 'initiative' action from Lele. The teacher explained and tackled with this in time, affirming Lele's behavior of "reminding" his peers of the rules of the game, and encouraging them to thank Lele for his "help". The teacher tried to connect Lele's words with "reminding and helping peers", hoping to inspire more "helping peers" languages and behaviors from Lele, and to promote initiative communications of Lele through the appropriate languages and behaviors intensification.

\subsection{Foster Their Communication Confidence by Way of Building a Performance Platform for "Advantages" of Autistic Children}

In order to promote the initiative communication of autistic children, it is of great importance to help them build up confidence in communications. In inclusive class environment, if autistic children can feel the recognition and acceptance by their peers, their communication confidence will also increase remarkably. Therefore, teachers should try to explore the "advantages" developmental part of autistic children and give them a platform to perform in front of the class. [13] In addition to developing self-confidence of autistic children, teachers should enable their advantages felt by the group, and thus enhance the group's acceptance of them. 
Table 3. Tiantian read ancient poems.

\begin{tabular}{ll}
\hline $\begin{array}{l}\text { Status of Tiantian } \\
\text { Interventions from the }\end{array}$ & $\begin{array}{l}\text { Relatively sensitive visual sense; stronger abilities to recognize Chinese characters than children of the same age; able to read all the } \\
\text { commonly used Chinese characters. } \\
\text { teacher }\end{array}$ \\
$\begin{array}{l}\text { The teacher invited Tiantian intentionally to read antient poems in language games and affirmed and appraised Tiantian's } \\
\text { performances. } \\
\text { Previously Tiantian did not pay much attention to such activities, since then Tiantian often raised his hands requesting to read } \\
\text { poems. } \\
\text { They expressed admiration for Tiantian's storage of ancient poems, and affirmed the advantages of Tiantian. Their interactions with } \\
\text { Tiantian were slightly boosted. }\end{array}$ \\
\hline
\end{tabular}

Table 4. Tiantian was great in math activities.

\begin{tabular}{ll}
\hline Tiantian's Status & Abilities of mathematics reached the level of the first grade, strong in calculation. \\
\hline $\begin{array}{l}\text { Interventions from the } \\
\text { teacher }\end{array}$ & $\begin{array}{l}\text { In mathematics activities, the teacher gave him more opportunities to answer and perform. In front of all children, the teacher } \\
\text { praised his active hand raising behavior, calculation ability and homework quality, and rewarded him in the meantime. }\end{array}$ \\
$\begin{array}{l}\text { Change of Tiantian } \\
\text { Attitude of the group }\end{array}$ & $\begin{array}{l}\text { Once there was an evaluation that "Tiantian is a mathematical genius". The recognition that "Tiantian is great in mathematical } \\
\text { activities" came into being. }\end{array}$ \\
\hline
\end{tabular}

In the language game segment or the story listening segment before lunch, teachers consciously invited Tiantian to recite ancient poems to demonstrate his special talents and helped him win everyone's attention and recognition. In mathematics activities, teachers gave Tiantian opportunities to answer questions and demonstrate in front of everyone his high-quality homework. The teacher's intentional highlight and appraisal of the outstanding performances of Tiantian in mathematics activities made the cognition of "Tiantian is great in mathematics activities" formed in the class. The teacher intended to let the appreciation and admiration for the advantages of Tiantian take into shape in the class, which are very important to Tiantian. They can not only establish his self-confidence of initiative expressions and voluntary demonstrations, but also facilitate his interactions with peers and smoothen the fellow group accepting and affirming him. [14]

\section{Research Conclusion and Discussion}

\subsection{Principal Research Conclusions}

Through continuous observations of the individual cases involved in the study, the researcher finds that the three strategies summarized in this study are of effectiveness for promoting initiative communication of autistic children.

First of all, understand the essence behind the "misbehavior" of autistic children and teach them the necessary communication skills. Autistic children being understood by teachers is the emotional support. While the acquisition of communication skills can help improve their communication effect and achieve their goals. Secondly, we should look for the "link" between autistic children and ordinary children to stimulate their initiative communication needs. With games as the carrier, build the bridge of communications between them and their peers, and make autistic children ignite the desire for initiative interactions and communications. Thirdly, tap their advantages and provide a platform to display them, so as to foster their communication confidence. Autistic children gain more recognition and even worship from regular children because of demonstration of their special skills, which helps them obtain a sense of belonging and thus foster their confidence of initiative communications.

The researcher believes that most autistic children do not have absolute language problems, instead, they have their own expression and communication ways. Appropriate strategical interventions from teachers in inclusive classes can promote the initiative communication of autistic children and improve their relationships with peers.

\subsection{Outlook for Further Study}

The three strategies summarized in this study all feature inclusive class teachers as principal designers and implementors. Indeed, it is true that inclusive class teachers, as class administrators, is an important other party that affects the initiative communications and social interactions of autistic children. However, the fellow in inclusive classes is also an important factor for the success of inclusive education. [15] In researches afterwards, the researcher would like to focus on "peer supporting in kindergarten inclusive education", to explore which aspects of peer supporting autistic children need in kindergarten daily activities, to examine the experimental strategies of peer supporting in inclusive education, and to probe into how to supervise and evaluate peer supporting for autistic children and so on.

\section{References}

[1] Lili ZHANG, Shaobo YANG, Xinmei OUYANG (2019). Research and exploration of teacher cultivation for preschool inclusive education. Modern Special Education, 04: 14-18.

[2] Yuanyuan LI, Qiaoyun ZHAO. (2019). Explorational analysis of teachers' cultivation for preschool inclusive education in China. Modern Special Education, 22: 48-53.

[3] Baijun PAN, Danni SUN, Fan JIANG. (2019) Research of current situations of preschool education in Tianjin [J]. Education and Teaching Seminar, 01: 50-52.

[4] Xiaoxu HE. (2018) Research on support of teachers' feelings in preschool inclusive education for autistic children [D]. Shenyang Normal University, 05. 
[5] Shumeng YAO. (2019) Case study of inclusive education for autistic children in D kindergarten. Sichuan Normal University, 03 .

[6] Xiuxi WANG, Xiaoyan ZHANG, Guanghua JIN, Yunci HU. (2014). Case study of preschool inclusive education for autistic children. Shijiazhuang College Paper, 05: 93-98.

[7] Fanshuai BU, Sheng XU. (2015) Diagnosis standards of autism spectrum disorders: evaluation, influence and outlook. [J]. Special Education in China, 02: 40-50.

[8] Gary B. Maxibov, Victoria Shea, Eric Shaopule. (2014) (US) The TEACCH Approach to Autism Spectrum Disorders, translated by Qiubaba, 04, 65-66.

[9] Xiaoyu MU. (2018) Experimental exploration into interventions of problematic behaviors of autistic children through "active behavioral supporting". Modern Special Education, 07: 66-69.

[10] Weihe HUANG, Xiayao CHEN, Dan LI. (2010) Method of pivotal skills training: new direction of applying $\mathrm{ABA}$ into interventional education of ASD children [J]. Special Education in China, 124 (10): 63-68.

[11] Nianli ZHOU. (2011) Games treatment for special children [M]. Peking University Press, 11, P3.

[12] Yuexin ZHANG. (2019) Research on "Inclusive Education" based on the synchronous development of autistic children and ordinary children [J]. Modern Special Education, 03: 29-32.

[13] Yanran CHENG, Zhenfang XIONG, Anni HE. (2018) Individualized interventional experiences of autistic children based on the theory of Multiple Intelligences. Nursing Journal, 01: 62-64.

[14] Yansheng PAN, Ling LV, Xiangrong LI. (2015) Happy friends accompany me to grow up--supportive games in kindergarten inclusive education for autistic children [M]. Peking University Medical Press, 03, P2.

[15] Wenying NIU. (2015) New paradigm of embracing individual differences--Inclusive Education (the second edition) $[\mathrm{M}]$. Psychology press Co., Ltd. 